DOI: 10.15587/2706-5448.2021.237296

Article type «Reports on Research Projects»

\title{
Yevhen Horobets \\ ESTIMATION OF THE ERROR OF THE SIMPLIFIED ALGORITHM OF PROCESSING OF FUNCTIONS OF DEFLATIONS OF DEFORMED FRAMES OF BODIES OF ROLLING STOCK
}

The study is aimed at assessing the size of the error that arises when processing the results of examining the geometric characteristics of the bearing structures of rolling stock units using an algorithm without using trigonometric functions. The object of the research is a method of simplified alignment of the deflection function of body frame beams to the horizontal plane. One of the biggest problem areas is the lack of understanding by some customers of the work of the possibility of using this algorithm due to the lack of information about the errors that arise in the simplified calculation.

The study was carried out by comparing the results of processing the initial data by two methods, obtained during the work on the inspection of the state of the supporting structures of the unit of the shunting diesel locomotive TGM6. One method, the algorithm of which is the subject of this study, assumes that no complex calculations are used during data processing. The second method involves the use of an algorithm for aligning the deflection functions of the body frame beams of a rolling stock unit of railways in the horizontal plane, taking into account all trigonometry tools, which will exclude the accompanying calculation errors of the simplified method.

After processing the initial data, two sets of results were obtained - with the desired calculation error and without. Comparison of these datasets yielded an error value for frame tilt of 5.7. For clarity, the size of the error was compared with the expanded uncertainty values of the main sources of uncertainty in the methodology for examining the bearing structures of rolling stock. On the basis of the analysis of two methods of leveling the inclination to the horizontal plane of the deformed rolling stock body frame, the expediency of such an approach has been proved.

The results obtained make it possible to reasonably use the Simplified approach to processing the data obtained during the survey of the geometric characteristics of the rolling stock. If necessary, the developed mathematical model can be used to improve the accuracy of calculating the uncertainty of measurements of geometric characteristics, as well as for use in the study of modification of existing or development of new measurement techniques.

Keywords: rolling stock, rolling stock inspection, body frame deformation, geometric characteristics, level, measurement error.

\section{How to cite}

Horobets, Y. (2021). Estimation of the error of the simplified algorithm of processing of functions of deflations of deformed frames of bodies of rolling stock. Technology Audit and Production Reserves, 4 (1 (60)), 20-24. doi: http://doi.org/10.15587/2706-5448.2021.237296

\section{Introduction}

The implementation of the international standard ISO 17025 [1] in the activities of testing laboratories involves the implementation of the scope of work based on the calculation of the characteristics of the method, in particular the measurement uncertainty. However, standardized test methods performed on appropriate equipment have approved schemes for calculating the uncertainties described in the relevant method standards, as well as specific requirements for the implementation of the method within the laboratory. The task of the laboratory is to prove that the laboratory has the ability to perform tests in accordance with the requirements of the method and the uncertainty of the result allowed by the standard that is, to verify the test method. However, in some cases, the laboratory needs to independently carry out a wide range of work in order to prove the correctness of the application of the method - that is, to validate the test method. Such a need arises if the measurement method is performed using equipment that is not foreseen by the standard, the method is used outside the specified scope, or a proprietary measurement method has been developed. The greatest challenge is the laboratory-developed method validation task. In this case, as a rule, the amount of work required to study the properties of the method is the largest. 
Inspection of industrial transport locomotives involves a whole range of measurements. Some of the methods from this complex are standardized, but the measurement of the geometric characteristics of load-bearing structures (LS) is not such. The existing methods for measuring LS deformations of rolling stock are usually unique. They are developed by enterprises for individual use, are described in the technical specifications of the enterprises and legally have local validity.

Control of geometric characteristics is widespread in construction, mechanical engineering and other branches. In particular, in shipbuilding, optical systems are used to inspect the technical condition of ships [2] and control installation work [3]. In mechanical engineering branch, the geometric characteristics of parts are monitored, which are subject to increased safety requirements $[4,5]$. The paper [6] considers the determination of the geometric parameters of the rail track using unmanned aerial vehicles and the method of photogrammetry. When examining engineering structures in [7-9], it is proposed to use high-precision instruments to build three-dimensional models from «point clouds». Also, the use of optical devices is considered as an alternative to the classical means of direct measurement [10].

A study of the literature on methods and means for measuring deformations of rolling stock bodies' frames showed that measuring these characteristics requires special equipment or a set of means installed on prepared sections of the railway track (Fig. 1).

The value of the geometric characteristics of the body frames are standardized by the repair manuals [11, 12] individually for each type and model of rolling stock. When inspecting locomotives of industrial transport in order to further increase the service life, the testing laboratory of LLC SPE Ukrtransakad uses a laser level. This tool helps to reduce the influence of the human factor on the measurement process. However, this approach requires additional mathematical processing of the measurement results.

Since the device provided for the survey method forms an absolute horizon line, which is at an angle to the abscissa axis of the conditional locomotive coordinate system, it becomes necessary to take into account the influence of this factor on the numerous data obtained.

A simplified approach to leveling the obtained data to the horizon, based on taking into account the predictably variable error depending on the angle of inclination of the body frame relative to the horizon. However, it becomes obvious that this approach gives the correct result only if the frame is not damaged (that is, it is level).

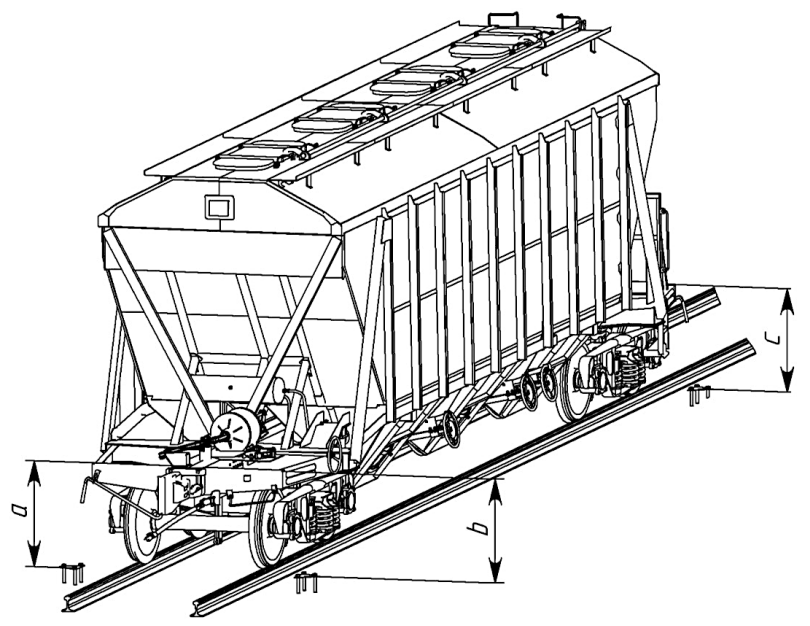

Fig. 1. Complex for measuring the flatness deviation of car frames using special platform-levels installed along the railroad rails

The aim of this research is to determine the need for accounting and calculating additional contributions to the measurement uncertainty when conducting surveys of the geometric parameters of the bearing structures of the rolling stock.

\section{Methods of research}

The following methods are used:

- analysis method when creating an algorithm for the complete calculation of the rotation of the deflection function of the locomotive body frame for alignment to the horizontal plane;

- comparison method for determining the sources of unaccounted for errors in the simplified calculation method; - measurement method was applied during the inspection of the technical condition of the TGM6 shunting locomotive, the results of which were the initial data for the research.

Fig. 2 shows a conditional model of an abstract locomotive, which is on an uneven track at the time of the survey.

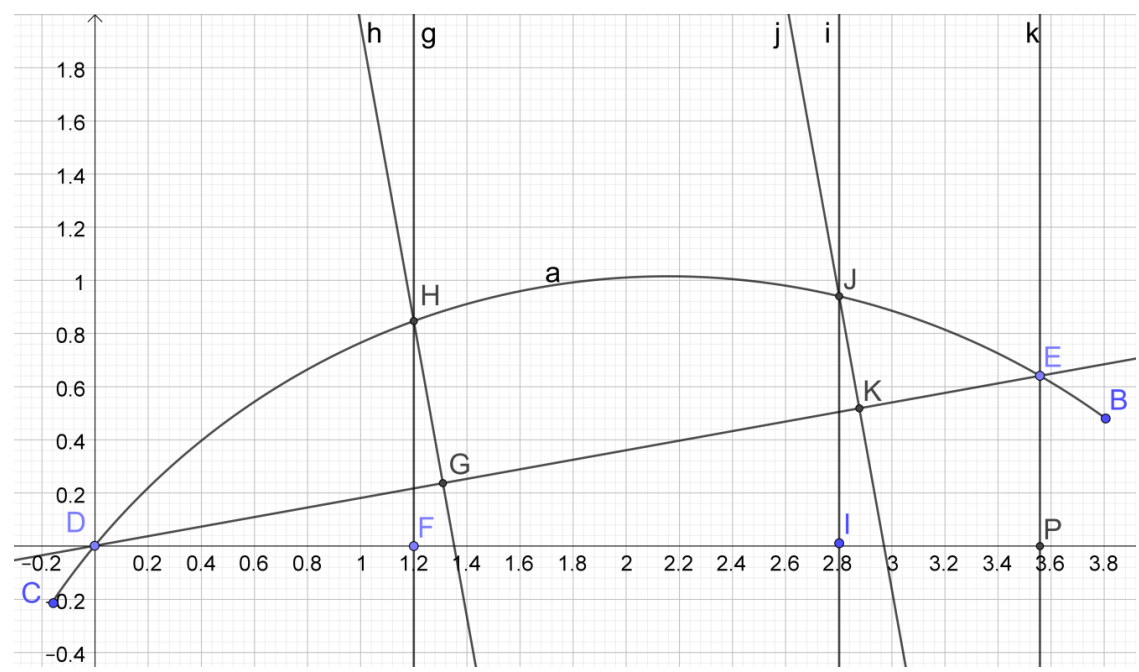

Fig. 2. Layout in space of the body frame of a conventional locomotive with a deflection in the vertical plane 
The locomotive frame a rests on the bogies at points $D$ and $E$. At point $H$, a control measurement of the deflection of the frame beam to body relative to the horizon level (laser level plane) $H F$ is carried out. But the real value of the deflection of the frame beam is the distance $H G$, the point $G$ of which is on the segment $D E$. It can be seen from the diagram that with an increase in the distance from the conditional zero point $D$, the measurement error increases - this aspect is visible when comparing the obtained heights at the control points $H$ (line $g$ ) and $J$ (line $i$ ). This component of the measurement error is predictable - it varies linearly from the zero point $D$, and at the point $E$ of the second support of the beam $a$, it is $E P$.

However, there is an additional error, the study of which is the purpose of this work. Let's draw a circle around point $\mathrm{H}$, which will pass through point $G$ (Fig. 3 ). That is, the radius of the circle is equal to the visibility of the real deflection of the frame beam.

In Fig. 4 it can be seen that between the real deflection $H G$ and the measured $H F$ there is an additional error $L N$.

Unlike the component of the error introduced by the tilt of the body frame, this component depends on the deformation of the frame beam.

The measurement technique assumes that the distance from the zero point $D G$ changes insignificantly when tilted, so $D G$ is equal to $D F$, and points $F, G, H$ lie on one straight line. However, to perform calculations, let's take this factor into account, since it is he who forms this unaccounted error.

When examining, there is a deviation value for point $E$ with the projection of $P$ on the abscis axis. And since it is calculated that this point is in the horizontal plane, the height $E P$, obtained at a point at a distance $D P$, sets the angle of inclination of the entire frame, where:

$$
\angle E D P=\tan ^{-1} \frac{E P}{D P}
$$

The NF height is equal to:

$$
N F=\tan (\angle E D P) \cdot D F
$$

from the zero point to the current control point.

The joint hypotenuse $D H$ is equal to:

$$
D H=\sqrt{D F^{2}+H F^{2}} .
$$

Hence there is the value of the real deflection $H G$ :

$$
H G=D H \cdot \sin (\angle H D F-\angle E D P)
$$

The $H L$ value is the radius of the circle o and is equal to the true deflection $H G$. Thus, the sought difference $L N$ is equal to:

$$
L N=H F-H G-N F .
$$

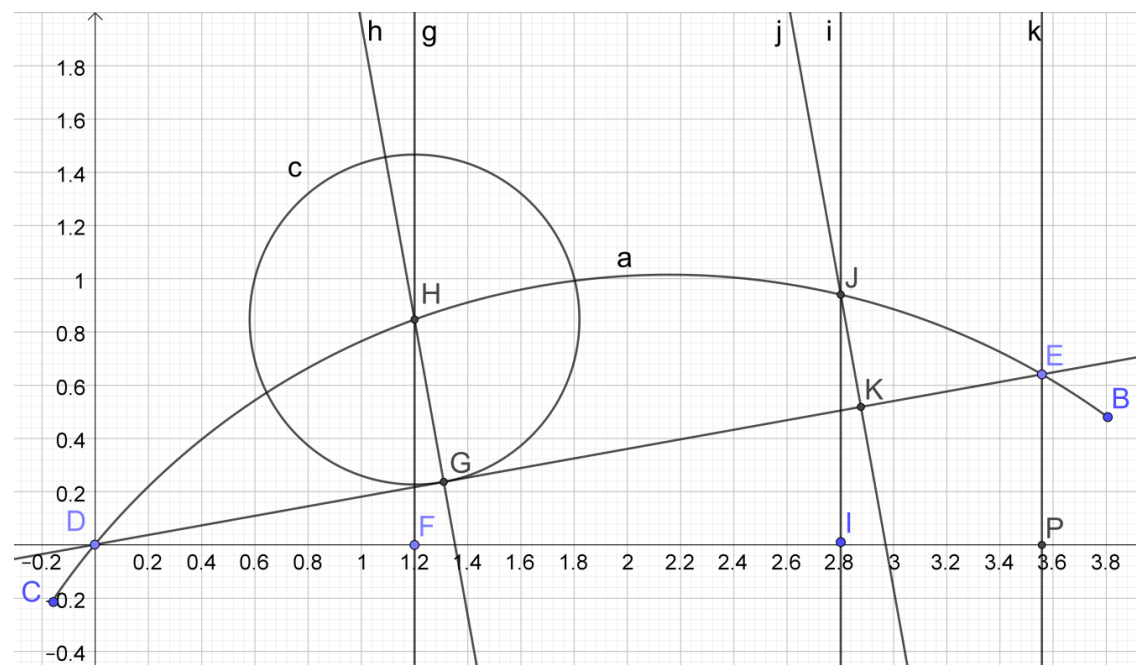

Fig. 3. Additional constructions on the lines of the control point $H$
Expanded formula for additional error:

$$
\begin{aligned}
& L N=H F-\sin \left(\begin{array}{c}
\tan ^{-1} \frac{H F}{D F}- \\
-\tan ^{-1} \frac{E P}{D P}
\end{array}\right) \times \\
& \times \sqrt{D F^{2}+H F^{2}}-D F \cdot \frac{E P}{D P} .
\end{aligned}
$$

\section{Research results and discussion}

When developing a mathematical model of alignment in the longitudinal axis of the locomotive frame, it was found that the value of the unaccounted error is influenced by two factors. 
The first factor is the tilt angle of the frame. As the angle increases, the difference between the actual deflection and the «frame - frame horizon» segment ( $G H$ and $H N$ in the illustration, respectively) increases.

The second factor is the actual height. With the same value of the angle between the lines of the perpendicular to the absolute horizon and the perpendicular to the frame horizon, the value of the $H G N$ unaccounted for in the triangle will increase in proportion to all other elements of the triangle (according to the principle of similar triangles).

The main, visually visible difference between the heights «point - frame horizon» and «point - absolute horizon» is fully calculated using the simplified alignment method.

Based on this, in a separate series of measurements, the dependence of the values of unaccounted errors at each individual point is related only to the value of the frame deflection height at this point. The position of the point on the body frame relative to the selected reference point does not affect the value of the unaccounted error, since this component is taken into account by both methods of processing the initial data.

To understand what error values can be expected, the data of one of the TGM6 locomotives surveyed by LLC SPE Ukrtransakad were additionally processed taking into account the theory outlined above.

A graph with the initial measurement data and the results of processing these data using a simplified alignment algorithm is shown in Fig. 5. Horizontal axis - distance in meters from the axis of the body frame kingpin, located under the driver's cab; vertical axis - heights from the selected horizon level to the lower flange of the body frame beam.

Table 1 shows the analysis of data changes during processing by two methods (simplified and complete methods). The columns have the following meanings:

1 - number of the measuring point on the length of the body frame (points were selected that lie in the positive part of the relative distance);

2 - distance from the zero point (level of the pivot axis under the driver's cab);

3 - primary data, from which the value of the zero point height was calculated;

4 - the size of the deformations of the body frame, calculated by a simplified method;

5 - full calculation of the deflection taking into account the additional error;

6 - the size of the predicted component of the deflection caused by the tilt of the body in space;

7 - the size of the measurement error of the method, is not taken into account in the simplified calculation.

As can be seen from the data in column 7 of Table 1 significant digits of the error value appear in the fourth digit after the decimal point in the case of deflection values close to the maximum permissible value of $15 \mathrm{~mm}$. In the case of smaller deflection values, significant numbers are in the fifth digit.

Table 2 shows the size of measurement uncertainties, the sources of which are measuring instruments and the size of the systematic error (not always by value, but predictable) caused by the calculation method.

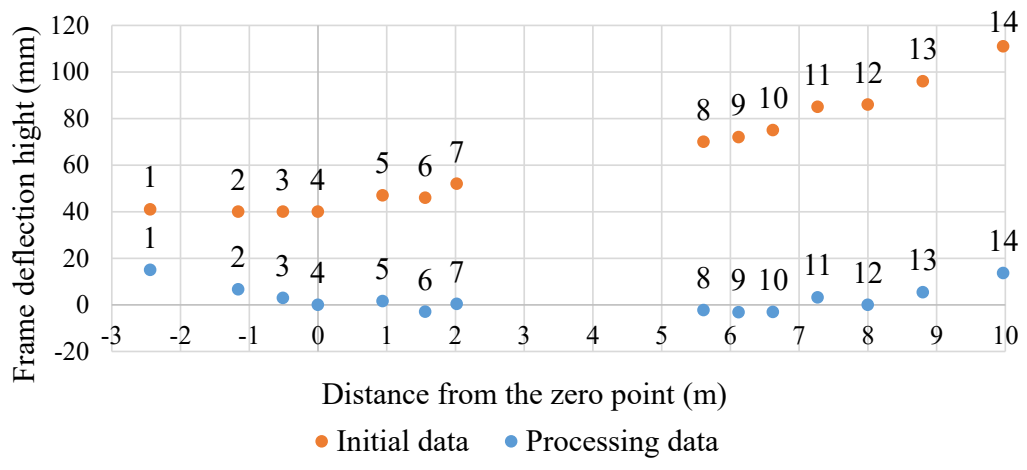

Fig. 5. Initial and processing data of the beams of the TGM6 body frame

Table 1

Analysis of changes in primary data during processing by two methods

\begin{tabular}{|c|c|c|c|c|c|c|}
\hline $\begin{array}{c}\text { Point } \\
\text { No. }\end{array}$ & $\begin{array}{c}\text { Distance from } \\
\text { zero (mm) }\end{array}$ & $\begin{array}{c}\text { Measured de- } \\
\text { flection (mm) }\end{array}$ & $\begin{array}{c}\text { Simplified deflection } \\
\text { calculation (mm) }\end{array}$ & $\begin{array}{c}\text { Complete deflection calcu- } \\
\text { lation (mm) }\end{array}$ & $\begin{array}{c}\text { Systematic component of the } \\
\text { slope in the original data (mm) }\end{array}$ & $\begin{array}{c}\text { Calculated error of par- } \\
\text { tial calculation (mm) }\end{array}$ \\
\hline 5 & 940 & 7 & 1.5950 & 1.594973633 & 5.4050 & 0.000026367 \\
\hline 6 & 1560 & 6 & -2.9700 & -2.9699550903 & 8.9700 & -0.000049097 \\
\hline 7 & 2020 & 12 & 0.3850 & 0.384993636 & 11.6150 & 0.000006364 \\
\hline 8 & 5610 & 30 & -2.2575 & -2.2574626882 & 32.2575 & -0.000037318 \\
\hline 9 & 6120 & 32 & -3.1900 & -3.189947267 & 35.1900 & -0.000052733 \\
\hline 10 & 6620 & 35 & -3.0650 & -3.064949333 & 38.0650 & -0.000050667 \\
\hline 11 & 7270 & 45 & 3.1975 & 3.197447143 & 41.8025 & 0.000052855 \\
\hline 12 & 7670 & 46 & 0.0000 & 1.897468633 & 44.1025 & 0.000031367 \\
\hline 13 & 8800 & 56 & 5.4000 & 5.399910733 & 50.6000 & 0.0000089267 \\
\hline 14 & 9970 & 71 & 13.6725 & 13.67227398 & 57.3275 & 0.000226018 \\
\hline
\end{tabular}


Table 2

Comparison of the dimensions of errors in measuring the geometric characteristics of the body frame of the TGMG diesel locomotive

\begin{tabular}{|l|c|c|}
\hline \multicolumn{1}{|c|}{ Source of error } & Calculation (if necessary) & Value (mm) \\
\hline $\begin{array}{l}\text { Extended uncertainty of the la- } \\
\text { ser level BDSCH PLL 360 (line } \\
\text { thickness) [3]* }\end{array}$ & $\frac{(2.5 / 2)}{\sqrt{6}} \cdot 2$ & 1.02 \\
\hline $\begin{array}{l}\text { Expanded measurement uncer- } \\
\text { tainty with a metal ruler }\end{array}$ & $\begin{array}{l}\text { Calibration certificate, cove- } \\
\text { rage factor } K=2\end{array}$ & 0.17 \\
\hline $\begin{array}{l}\text { A systematic error was calcu- } \\
\text { lated for a bend of } 13.6 \mathrm{~mm}\end{array}$ & $\begin{array}{l}\text { Calculation by model in the } \\
\text { article }\end{array}$ & 0.00023 \\
\hline
\end{tabular}

Note: ${ }^{*}$ - the deviation from the horizon of the line of the circular laser level is minimized by optimizing the layout of the level relative to the object to be examined.

As it is possible to see from the Table 2, the magnitude of the error has such a magnitude that rounding up the maximum error with the appearance of one in the first zero digit before significant digits is a ghost to any influence on the measurement results.

This study has limitations.

First, no error data are given for the negative direction of the frame length. These data require additional modification of the formulas, through the visibility of the distance values. However, as it was found earlier, for a specific series of measurements, only the actual deformation of the frame beam affects the value of the error, is investigated.

Second, the study was conducted for one specific survey result, since the goal was to estimate the order of error. Thus, variations in the tilt angle of the body frame were not considered.

Further areas of research can be as follows:

- determination of the influence of the angle of in-

clination of the frame on the size of the error;

- determination of the influence of the transverse inclination of the vehicle body on the projection of the surface relief of the beam is being investigated.

Nevertheless, the available results of the current study indicate errors of much smaller orders of magnitude than the measurement results, and therefore the expediency of carrying out further studies requires justification.

\section{Conclusions}

The author analyzed the technique of simplified mathematical alignment in the space of models of deformed frames of bodies of rolling stock of railways. The results of the analysis give reason to conclude that the size of the error has such a degree of significance that it can be neglected and a simplified method for leveling the frame model in space can be used in order to reduce the complexity and volume of calculations.

Analysis of the complete algorithm for aligning the body frame in space and the processes occurring in the data provide the following information for conclusions:

- the value of the unaccounted error caused by the refusal to use trigonometric functions in the simplified calculation algorithm depends on two factors: the angle of inclination of the body frame of the PC unit in space and the actual value of the frame deflection; - the component of the inclination of the frame beams, calculated on the basis of the points of the body frame supports on the bogies, is the main component in the difference between the values obtained experimentally and the actual values of the deflections;

- the value of the unaccounted error can theoretically reach one thousandth of a millimeter. However, such errors cannot affect the measurement results. There is no need for determining the systematic error or for additional calculations, there is no measurement uncertainty;

- the low size of the error makes it impractical to use a more complex algorithm for bringing the body frame to the horizontal plane;

- a simplified calculation algorithm allows for a preliminary calculation at the test site with or without elementary computer technology and is more useful from a practical point of view.

\section{References}

1. DSTU EN ISO/IEC 17025:2019 Zahalni vymohy do kompetentnosti vyprobuvalnykh ta kalibruvalnykh laboratorii (EN ISO/IEC 17025:2017, IDT; ISO/IEC 17025:2017, IDT) (2021). Kyiv: DP «UkrNDNTs», 30.

2. Blaschuk, V. N., Bunov, I. A., Khoang, Sh. M., Lubenko, V. N. (2011). Teoreticheskie osnovy primeneniya lazernykh takheometrov v izmeritelnoy sisteme, privyazannoy k korpusu sudna. Vestnik AGTU. Seriya: Morskaya tekhnika i tekhnologiya, 2, 13-19.

3. Nguen, Ch. A., Lubenko, V. N. (2014). Use of tacheometer sensors in quality control systems in shipbuilding. Vestnik AGTU. Seriya: Upravlenie, vychislitelnaya tekhnika i informatika, 2, 52-57.

4. Seredovich, A. V., Ivanov, A. V. (2005). Kontrol geometricheskikh kharakteristik elementov elektricheskikh mashin metodom lazernogo skanirovaniya. Interekspo Geo-Sibir, 1.

5. Pimshin, Yu. I., Naumenko, G. A., Postoy, L. V., Burdakov, S. M. (2017). Monitoring of the Nuclear Engineering Large Size Products. Globalnaya yadernaya bezopasnost, 2 (23), 47-55.

6. Ćmielewski, K., Gołuch, P., Kuchmister, J., Wilczyńska, I., Ćmielewski, B., Grzeja, O. (2021). Detection of crane track geometric parameters using UAS. Automation in Construction, 128, 103751. doi: http://doi.org/10.1016/j.autcon.2021.103751

7. Skvortsov, B. V., Malysheva-Stroykova, A. N., Chernykh, A. V. (2016). A method of the laser-television control of geometric parameters of objects with complex shapes. Instruments and Experimental Techniques, 59 (1), 63-68. doi: http://doi.org/ $10.1134 / \mathrm{s} 0020441216010310$

8. Demkin, V. N., Stepanov, V. A., Shadrin, M. V. (2013). Rapid prototyping systems with laser scanning. Nauchno-tekhnicheskie vedomosti SPbGPU. Fiziko-matematicheskie nauki, 3 (177), 136-143.

9. Danilov, V. A., Fedorov, A. V., Bezvershenko, L. S. (2019). The Comparison of the Methods of Photogrammetry and Laser scanning for the Establishment of three-Dimensional Models of objects and territories of Archeological GIs (on the Example of the Archeological Excavation of Uvek Hillfort). Izv. Sarat. un-ta Nov. ser. Ser. Nauki o Zemle, 2, 72-78.

10. Li, D., Wei, R., Du, Y., Guan, X., Zhou, M. (2017). Measurement methods of geometrical parameters and amount of corrosion of steel bar. Construction and Building Materials, 154, 921-927. doi: http://doi.org/10.1016/j.conbuildmat.2017.08.018

11. Rukovodstvo po srednemu i kapitalnomu remontu teplovozov tipa TEM2. RK 103.11.304-2003 (2003). Moscow, 125.

12. Teplovoz TGM6A. Rukovodstvo po sredneтu i kapitalnomu remontu. 24.02.05.21-83 RK (1985). 42

Yevhen Horobets, Specialist, Limited Liability Company «Scien tific and Production Enterprise «Ukrtransakad», Dnipro, Ukraine, e-mail: gorobets.eugene@gmail.com, ORCID: https://orcid.org/00000001-8017-1595 